\title{
Actualidad del mensaje de «El Español» de Blanco White
}

\author{
Eduardo Varela Bravo
}

El CL aniversario de la muerte de José María Blanco White (Sevilla 1775 Liverpool 1841) es una buena ocasión para cuestionarse la validez y actualidad del pensamiento de este intelectual heterodoxo en la España de hoy en día más allá de reivindicaciones personales o justicias históricas ${ }^{1}$. Vale la pena preguntarse si todavía existen en España las razones que le llevaron al cambio de país, de religión y de cultura o, por el contrario, si estas causas han desaparecido. En este último caso, queda por saber si la desaparición de las tensiones por él observadas en España se deben al cumplimiento de aquellas medidas que Blanco White recomendó en su día para hacer de nuestra patria un país habitable para todo tipo de pensamientos. Si esto fuera así, Blanco White habría conseguido, más allá del interés de la heterodoxia de vida y obra, un cierto don profético y, por tanto, una clarividencia analítica de cuáles eran los principales problemas de España en los primeros momentos de su historia contemporánea. Esto es lo que pensamos estudiar aquí tomando como base las ideas políticas, sociales y religiosas formuladas por Blanco White en El Español, publicación periódica que escribe solo en Londres entre 1810 y $1814^{2}$, cuando España está sumergida en plena Guerra de la Independencia y, simultáneamente, en la revolución política representada por las Cortes de Cádiz que daría origen, entre otras cosas, a las dos tendencias que, de una forma u otra, han estado presentes en España hasta la fecha: la conservadora o servil, partidaria del absolutismo y del autoritarismo y la liberal que, si bien trata de defender ideales como los de libertad, igualdad y justicia, no deja en su praxis política de ser tan

\footnotetext{
${ }^{1}$ Hace poco tiempo se ha publicado una biografía de Blanco White en la que se ofrece una vision equilibrada de su vida y obra: Murphy, M: Blanco White. Self-Banished Spaniard. New Haven and London, Yale University Press, 1989. Este trabajo va más allá de la simpatía de Vicente Lloréns o de la reivindicación de la heterodoxia de Juan Goytisolo, por lo que es muy recomendable para desmitificar el entusiasmo por el heterodoxo Blanco, tan falso, a nuestro parecer, como la anterior condena que sobre él pesaba. El Dr. Manuel Moreno Alonso parece tener también casi en prensa un libro sobre la vida y obra de Blanco White que sin duda arrojará más luz sobre nuestro personaje.

${ }^{2}$ El Español. Londrés, Imprenta de C. Wood, Abril 1810-Junio 1814. Esta obra ha sido estudiada en detalle por Varela, E. en: B lanco White periodista político. Tesis doctoral, Universidad de Sevilla, Junio 1987.
} 
intolerante como la anterior. Esta situación provocará, ya lo escribe Blanco White desde El Español, un estado de guerra permanente y a la alternancia traumática de las dos Españas tras la vuelta de Fernando VII. La historia no ha hecho sino dar la razón a esta visión general de España de Blanco White. También se la da en su consideración de que el Rey es pieza clave en la posible solución al conflicto. Aquí encontramos la primera señal de su modernidad.

«El partido que ha sido destronado, no puede ser extinguido: cada generación que vaya apareciendo, la flor de los españoles que están creciendo ahora, se halla destinada por una necesidad inevitable a aumentar las fuerzas de aquel bando: en cuanto alcanza la previsión en materias tan variables por las circunstancias: $\mathrm{Me}$ atrevería a decir que no puede pasar medio siglo sin que el trono español se halle otra vez vacilante, y la nación entregada a la anarquía, a no ser que ese mismo rey que aborrece y detesta el despotismo y que asegura que «las luces y la cultura de la nación no lo sufren ya» se persuada de que menos sufre la tiranía a intelectual en que, me temo, quiere conservar a su reino» ${ }^{3}$.

Blanco White, antes de abandonar España desde Cádiz en 1810 había defendido posiciones políticas radicales desde la tribuna periodística de El Semanario Patriótico ${ }^{4}$. En esencia, abogaba por una monarquía, e incluso ponía ésta en duda, sustentada en la soberanía popular y en la abolición de privilegios. Algo tan radical que, junto con sus comentarios sobre la actualidad política y los comentarios militares del coeditor Isidoro de Antillón, asustó a los miembros de la Junta Central, que hizo cerrar la publicación. Al leer El Semanario Patriótico poco hay que diferencie a Blanco del pensamiento liberal tal y como se va a plasmar en la actuación de las Cortes de Cádiz posteriormente, salvo en su radicalismo. Pero, para cuando se promulgue la Constitución de 1812, Blanco habrá ya madurado sus ideas al ver a su país desde la distancia y, sobre todo, al haber estudiado los fundamentos y el hacer políticos de su país de adopción: Inglaterra. En las páginas de El Español se comprueba claramente esta evolución de sus ideas de suerte que, sin ser nunca un servil, adoptará una postura de independencia crítica que molestará a los liberales españoles hasta el extremo de declararle enemigo de España, contribuyendo en gran medida a su leyenda negra.

De sus soluciones liberal-moderadas para España nos interesa recalcar aquí cuatro puntos: tolerancia religiosa, equilibrio parlamentario, flexibilidad en el problema de América, con tratamiento en pie de igualdad entre españoles y americanos y necesidad de elevar el nivel cultural del país. Dejamos aparte la propuesta que sin duda ocupa más espacio en las páginas de El Español: la alianza incondicional con Inglaterra tanto en política exterior como en estrategia militar, ya que este último aspecto se encuentra más lastrado por el tiempo y corresponde a otro tipo de estudio: la conveniencia o no de semejante paso en esa coyuntura histórica determinada.

\footnotetext{
${ }^{3}$ El Español 47, 1814, pp. 307-308.
}

${ }^{4}$ Sobre esta publicación ver Varela, E. Tesis citada y «Un periodista radical: Blanco White en el Semanario Patriótico». Sevilla, Archivo Hispalense 215 (1987) pp. 127-142. 
Si constatamos en las páginas de El Español una moderación progresiva de ideas, constatamos también un profundo desencanto a partir de la promulgación de la Constitución de Cádiz. Blanco critica fuertemente este texto legal, que considera rupturista y segura fuente de enfrentamiento con el retorno del Rey, y busca desesperadamente medidas que puedan equilibrar la situación. Blanco nota con acierto que está a punto de escaparse una oportunidad única de regeneración histórica y lanza una serie de propuestas cuya actualidad resalta en la España democrática de hoy en día, si bien en su época cayeron en el vacío.

En este artículo vamos a dejar para el final el problema de la intolerancia, ya que está constituye la piedra de toque de todo el edificio conceptual de Blanco. Es precisamente el caso de intolerancia el único en el que en vez de flexibilidad y pragmatịsmo pide decisión a los liberales mostrándose, paradójicamente, por ello más «liberal» que ellos. Vamos, pues, a abordar primero otros puntos que contribuyen progresivamente al sistema político equilibrado que ha de contar con la tolerancia como base.

Convencido de la bondad del sistema inglés, Blanco White no deja de recomendar a los liberales españoles, además de pragmatismo y prudencia en su actuar, que utilicen el método que tan buen resultado ha dado en su país de acogida donde, sin necesidad de estridentes declaraciones de soberanía popular, se puede costreñir el poder real por medio del control del presupuesto y pormedio de una efectiva igualdad jurídica de todos los ciudadanos ante la ley. Una medida complementaria es ganarse la buena voluntad de nobles y prelados por medio de la creación de una segunda cámara parlamentaria donde éstos puedan tratar los asuntos públicos y velar por sus intereses. Esta propuesta, repetida antes de la promulgación de la Constitución, se hace insistente después de ella, ya que el principio de soberanía popular chocará frontalmente con las pretensiones del Rey:

«Póngase freno al poder; pero que no lastime: sujétensele las manos sin envarárselas; pero sea con lazos de seda que más parecen adornos que prisiones. De no, una de las dos cosas ha de perecer; o el lastimado, o lo que lo lastima. Esta será la suerte de la Constitución española si no se corrige en tales puntos. En tanto que no haya rey, y que el poder ejecutivo esté en una regencia; el choque no será fuerte, porque los regentes tolerarán sin gran dificultad la dependencia que se les hace probar a cada instante. Estos por grandes personajes que sean, están acostumbrados a ella y se figuran que son ministros con más honores y poderes que los anteriores. Pero llegue a ponerse en el trono una persona real, y verán las Cortes cuán vano es el triunfo que han ganado en ausencia del contrario. Verán cuan imprudente han vestido la precaución con visos de orgullo»s.

Blanco, pues, busca una evolución política similar a la que se sancionó en Inglaterra con la «Gloriosa Revolución». Hay que buscar un equilibrio práctico, realista, entre los distintos poderes más allá de teóricas alusiones a la soberanía popular:

${ }^{5}$ El Español 25, 1812, pp. 78-79. 
«El único modo de combinar bien estos poderes fue hallado por los profundos políticos que dieron la última mano a la Constitución inglesa, dejándola como está la presente. Pusieron el poder ejecutivo en manos del rey; mas no del modo que indica la división metafísica, sino como lo exige la sabiduráa práctica, y el profundo conocimiento del objeto a que esta división se dirige. Dieron exclusivamente al rey el encargo de hacer ejecutar las leyes; pero no le negaron parte directa en formarlas. Asf lograron reducir la monarquía a sus justos límites, destruyeron en su rarz al despotismo sin degradar al trono de la altura en que estaba; y dejándole brillo y poder bastante para la satisfacción propia del que lo ocupase en cualquier tiempo, y para la veneración y respeto de los pueblos que habfan de obedecerle» ${ }^{6}$.

Preocupado por lo radical de la medida de las Cortes de Cádiz, no es de extrañar que pida también una «cámara de los lores» con el fin de equilibrar el sistema político español. Máxime cuando el hacer político de los liberales ha puesto a nobles y prelados en contra de las reformas engrosando las filas del partido llamado servil:

«España está pendiente del arbitrio, capricho y despotismo de la mayorfa de sus Cortes, sin ningún poder establecido que modere la precipitación, o contenga la injusticia en que pueden incurrir todo cuerpo que decreta a mayoría de votos, sin formas que hagan dificultosa la intriga y den lugar a la reflexión.

Esta proposición, que a mi parecer es evidente más que la luz del día, indica, con la misma evidencia, su natural remedio: y es que las Cortes dividan el poder de que se han apoderado. El mejor medio de hacerlo serfa formar otra Cámara legislativa compuesta de los representantes de la grandeza y el clero. Llamados de este modo a la participación del poder político que han gozado desde los tiempos más remotos, por la Constitución española, no se mirarfan como cuerpos ofendidos en el presente estado de cosas»?

En las palabras escritas por Blanco White resuenan, más allá de su vivencia personal del estado político de Inglaterra, las ideas moderadas de Burke y Jovellanos, a quienes hace justicia en El Español ${ }^{8}$. Si comparamos lo defendido por Blanco con lo sucedido en nuestro país en los últimos tiempos vemos que, evidentemente, España ha tenido que adoptar soluciones originales a su particular situación política. No se ha copiado fielmente el modelo inglés. Sin embargo, como punto de coincidencia está el moderantismo y pragmatismo de la reforma española que hizo desembocar un sistema dictatorial en una monarquía moderada constitucional en el que el papel y el peso de la Corona es reconocido sin merma para la soberanía de la nación y donde se ha procurado la armonización de intereses. No se trata del triunfo de la España liberal sobre la conservadora, sino de la convivencia de ambas bajo una monarquía democrática en la

${ }^{6}$ L.b. 26, 1812, p. 120.

${ }^{7}$ Ib. 38, 1813, pp. 419-20. pp. 3-19.

${ }^{8}$ Se basa en Burke para escribir su importante: «Variaciones polfticas del Español . El Español 33, 1813,

Hace justicia a Jovellanos en un parde artículos: «Fallecimiento del Señor Jovellanos», 21, 1811, pp. 230239 y «Don Gaspar de Jovellanos a sus compatriotas», 22, 1812, pp. 279-325. 
que el Rey, respetado, ha dado muestras claras de su interés por mantener el sistema vigente. Baste recordar el 23 de Febrero de 1981. La estabilidad política española debe mucho a ese espíritu conciliador e integrador bajo el que surgió, un espíritu que sin duda aplaudiría un Blanco White pendiente en 1812-14 por el posible enfrentamiento de las dos Españas y la vuelta de la monarquía absoluta como resultado de la agresividad liberal. Aquí tenemos un segundo punto de contacto entre lo expresado por Blanco White y la España actual.

Otro punto de interés constante en El Español es la problemática de la independencia de las colonias americanas. Blanco adopta el difícil papel de ser valedor de sus primeras reivindicaciones de autonomía justificándolas en la necesidad de la igualdad de trato con España por razones de evolución histórica. Esta postura fue la desencadenante de su condenación por parte de las Cortes de Cádiz, que basaron su actuación en una burda maniobra política y que hicieron de Blanco el «Juan Sintierra» de sus artículos más duros. También es cierto que Blanco White, que siempre abogó por el entendimiento entre metrópoli y colonias, nunca defendió la independencia plena de éstas últimas. Lo que también le provocó polémicas con intelectuales americanos ${ }^{9}$. Dos son las ideas que resaltan del pensamiento de Blanco White: que las colonias americanas se ven forzadas a la independencia por la intransigencia española -ésta refuerza la labor de grupos radicales de corte jacobino similares, paradójicamente, a los liberales españoles- y su defensa de un hermoso sueño que no pudo llevarse a cabo: la formación de una especie de «Commonwealth» bajo la dirección de la monarquía española que colocaría a todos sus integrantes en pie de igualdad y sería el origen del surgimiento de una potencia hispanoamericana. Las Cortes de Cádiz, acogiendo a representantes americanos en pie de igualdad con los españoles se convertirían en el «congreso de ambos mundos». En las circunstancias críticas en las que vive España, América, en caso de desastre se convertiría en la heredera y refugio de la nación española:

«Entretanto que esta unión pudiera verificarse, las Cortes de la península sólo deberían tomar una medida respecto de la América: una sola y generosa: Renunciar a toda pretensión de superioridad sobre aquellos paises y convidarles a que (los que no lo hayan hecho) nombren sus gobiernos interiores y económicos, y en seguida envien sus diputados al congreso de ambos mundos. Hecho esto en nada debieran emplearse sino en tomar medidas eficaces contra el enemigo que ocupa la España. Si cuando llegasen los diputados de América y Asia, el cielo hubiera favorecido las armas de los que pelean por la patria, desde el emporio de ella pudieran echarse los cimientos del imperio más glorioso que se habría visto en el mundo. Si por el contrario el cielo permitiera que completase su triunfo la injusticia, jamás habría visto el universo surcar los mares expedición más gloriosa que la que llevara en su seno a la

9 Ver la Introducción de Lloréns, V. a su: José Maria Blanco White. Antología de obras en español. Barcelona, Labor, 1971. Es interesante leer lo escrito por el propio Blanco en su autobiografía: The Life of the Reverend Joseph Blanco White, written by Himself with portions of his Correspondence. Vol. I, p. 201-204. London, John Chapman, 1845. Sobre la polémica que Blanco mantiene con el independentista americano Mier ver Varela, Tesis citada pp. 299-318. El artículo clásico sobre esta polémica es: Simmons, M. E.: «Una polémica sobre la independencia de Hispano-Américar. Boletín de la Academia Nacional de la Historia. Caracas XXX (1947), pp. 82-125. 
nación española, a quien le sobran países en que existir feliz, gloriosa, eindependiente, aun cuando perdiera aquellos a quienes debe su nombre» ${ }^{10}$.

Las ideas de conciliación de Blanco han sido desechadas en la evolución histórica de las relaciones entre la madre patria y las colonias. Sin embargo, ciento cincuenta años después, siguen teniendo atractivo y, en cierto modo, vigencia. La festividad del Quinto Centenario del descubrimiento de América ha despertado el interés por estrechar las relaciones entre España y los países latinoamericanos. Desde esta perspectiva, las ideas de relaciones de igualdad, cooperación y entendimiento político y económico de Blanco tienen plena actualidad. Más aún si tenemos en cuenta, con respecto a la cuestión de la mezcla de razas que se da en América -y de la que se vuelve a hablar ahora- que Blanco, inspirado por la labor de Wilberforce en Inglaterra, es el primero en levantar su voz contra el tráfico de esclavos entre África y las colonias españolas defendiendo la condición de seres humanos de los negros:

«El modo de argüir de los que colocan a los negros en un grado de inferioridad intelectual propia y característica de los africanos es seguramente muy raro. Para concederles el mismo grado de perfectibilidad que a las demás naciones del mundo, tenemos una razón muy obvia: y es que el negro no carece de ninguna de las facultades que forman la esencia del entendimiento humano. ¿De qué operación del entendimiento es capaz el europeo de que no sea capaz el negro? Pues por lo que hace al grado de imperfección en las que poseen los africanos, por grande que quiera suponerse, no es mayor que la que vemos en muchos individuos nacidos en el centro de Europa. Para estos no hacemos una división en la escala intelectual, ¿y la haremos para los negros? Pero la gran razón para esto es que se distinguen de nosotros en la forma del cuerpo ¡ Extraño argumento! ¿Cómo que valdrá para el filósofo lo poco corporal en que se distinguen de nosotros, más que lo intelectual en que conviven? ¿Y esto tratándose de una clasificación que se ha de hacer en cuanto al entendimiento?» ${ }^{11}$.

Frente a colonialismo, igualdad de trato y solidaridad; frente a esclavitud igualdad de todos los hombres. El mensaje de Blanco es claramente actual dadas las cuestiones que se suscitan con motivo del quinto centenario del descubrimiento de América.

Para nosotros, en El Español de Blanco White se pueden distinguir dos etapas claramente diferenciadas: una etapa colaboradora, en el período anteriora la promulgación de la Constitución de Cádiz, en la que Blanco muestra su ilusión por colaborar en el nacimiento de un nuevo sistema político desde Londres y otra testimonial, tras la Constitución, en la que convencido de lo deficiente del sistema creado, propone medidas

${ }^{10}$ El Español 5, 1810, p. 377.

VerSeco Serrano, C.: «Blanco White y el concepto de revolución atlántica» en Laprensa en la revolución liberal. España, Portugal y América Latina. Actas del Coloquio Internacional de 1-3 abril 1982. Editor, A. Gil Novales. Universidad complutense de Madrid, 1983. También: Moreno Alonso, M.: «La independencia de las colonias americanas y la política de Cádiz (1810-1814) en El Español de Blanco White. Sevilla, 1985.

${ }^{11}$ El Español 19, 1811, pp. 8-9. Blanco publicó posteriormente un folleto antiesclavista: Bosquejo del comercio de esclavos y reflexiones sobre este tráfico considerado moral, política y cristianamente. London, Ellerton y Henderson, 1814. 
a la desesperada para tratar de enmendar el estado de cosas sancionado por la Constitución. En estos momentos, Blanco escribe para una España que ya no es, definitivamente, su patria; en octubre de 1812 se hace anglicano. Sin embargo continuará lealmente la publicación de El Español hasta el retorno al absolutismo de $1814^{12}$.

Un aspecto por el que Blanco muestra especial interés, por considerarlo básico para una estabilidad política y social en España, es la educación. A ella dedica varios artículos en su publicación. Tres son básicamente las medidas que propone: en primer lugar un proyecto educacional básico, para el que se pueden utilizar los modelos de Bell y Lancaster tan de actualidad en la Inglaterra de su tiempo, donde los alumnos se hacen casi inmediatamente profesores de alumnos de nivel inferior, una importante campaña de traducciones, sobre todo de manuales científicos sencillos que permitan poner el nivel de conocimientos de España a una altura similar al de los países europeos desarrollados y, en tercer lugar, fruto de su visión pragmática de las cosas, la utilización de los miembros de las compañías religiosas, en cuestión por las Cortes, para la enseñanza en aquellos puntos donde se encuentren. Todo ello, como ya hemos dicho, con el fin último de levantar el estado intelectual del país. Este aspecto no hace sino confirmar uno de los temas favoritos de Blanco White: el de la educación, ya presente desde suépoca en España como colaborador del Instituto Pestalozziano ${ }^{13}$. Hay que reseñar también que su convencimiento de la bondad de las traducciones se hace pantente en $E l$ Español dỏnde él mismo realiza numerosas traducciones, fundamentalmente de orden político, para ilustrar a los españoles de la península. Blanco está convencido de que las clases intelectuales españoles han recibido, debido fundamentalmente a la acción nefasta de la Inquisición, una formación deficiente y parcial, basada sobre todo en los más virulentos tratados de la escuela francesa ${ }^{14}$. Convencido de que esta educación deficiente es en gran medida productora del modo de hacer radical de los liberales, trata de equilibrar la balanza con traducciones de sino más moderado -Burke, Paley-, con revisiones históricas del hacer político de las antiguas cortes de la península y con la reivindicación, ya mencionada, del parecer de Jovellanos ${ }^{15}$. Por último, con respecto a la cuestión de las órdenes religiosas, Blanco no se deja llevar por el radicalismo esperado en una persona absolutamente convencida de la necesidad de la tolerancia y totalmente crítica con respecto a la Iglesia Católica como instrumento de opresión intelectual en España. Blanco critica el estado de la educación y la vida en los monasterios, pero sugiere que, reformados, pueden tener un papel en la educación del país, especialmente en el caso de los jesuitas, para los que Blanco tiene palabras de elogio.

Con respecto a la primera de las cuestiones aquí apuntadas, no podemos dejar de citar a Blanco acerca de las excelencias de la educación en las clases pobres:

12 Ver Varela, E. Tesis doctoral, conclusiones, pp. 669-691.

${ }^{13}$ VerLloréns, V.: «Blanco White en el Instituto Pestalozziano». Homenaje a Antonio Rodríguez Moñino. Madrid, Castalia, I, 1966, pp. 349-365.

${ }^{14}$ Especialmente claro en «Variaciones políticas del Español» antes mencionado. Ver nota 8.

${ }^{15}$ Se puede encontrar índice de todos los artículos de Blanco ordenados temáticamente en Varela, E. Tesis doctoral. 
«Las ventajas que tanto el gobiemo como las clases acomodadas de la sociedad puedan sacar de que las clases pobres sepan leer, son tan varias, numerosas y trascendentales, que serfa difficil pintarlas exactamente, o recogerlas en un punto de vista. Pero cualquiera reconocerá, sin necesitar de una reflexión profunda, que la mejor base de la subordinación, es la racionalidad, la suavidad, y moderación que el hábito de leer produce: que la facilidad de hacerse oŕr de todos los individuos de la sociedad por oscuros que sean es un punto de la mayor importancia para los gobiernos, y que no pueden lograrse sin que el arte de leer se halle universalmente extendido. Una nación en que no hay jornalero que no lea alguno de los papeles públicos, debe adquirir una especie de cultura general utilísima a las clases inferiores; pero infinitamente a todos los que por su mayor riqueza estarian, si esto no fuese así, a merced de un populacho feroz e indigente» ${ }^{16}$.

Blanco no llega a abordar en El Español el tema de la enseñanza superior. En su lista de prioridades está en primer lugar la cultura científica media, para lo que propone un vasto plan de traducción que debe estar apoyado por el Estado:

«No son grandes establecimientos cientfficos los que hace más falta en España. Medios de difundir el saber hasta las clases inferiores con proporción a sus circunstancias es lo que deben procurar con el mayor empeño todos los amigos de la prosperidad de aquel reino. Para esto sería conveniente que el gobierno convidase a los literatos españoles a buscar, traducir, y acomodar al pars, las obras que se han escrito en Inglaterra y Francia, cuyo objeto es popularizar por decirlo asf, las ciencias, y extender el conocimiento de sus aplicaciones prácticas a cuantos objetos lo requieren para su perfección, aún entre los que aparecen más mecánicos y remotos de las investigaciones cientfficas. Este primer paso es tan fácil que el gobiemo español sólo necesita quererlo para conseguirlo ${ }^{17}$.

El Estado no ha de desechar ningún recurso para el fin de conseguir la educación del pueblo. Como ya hemos comentado antes, hasta las órdenes religiosas, pese a su deficiente estado, pueden servir, si reformadas, para estos fines. El modelo son los jesuitas:

«No debe haber convento en ningún pueblo de España en donde no tuvieran casa los jesuitas. La razón de este extraño principio es que nadie ha tenido tando saber práctico en esta materia como los miembros de aquel instituto. Los conventos que existan deben mantenerse con la disciplina; decoro y ocupaciones que los jesuitas sostuvieron hasta su extinción»"

La preocupación de Blanco por la educación como fuente de estabilidad política y como elemento necesario del progreso de España es evidente. Para nosotros, las ideas de Blanco lo conectan por un lado con las inquietudes del período ilustrado anterior, por

${ }^{16}$ El Espariol 45,1814, p. 8.

${ }^{17} \mathrm{Ib} .47,1814$, p. 214.

${ }^{13} \mathrm{Ib} .34,1813$, p. 186. 
el otro con intentos renovadores de la educación que, como la Institución Libre de enseñanza, han tratado de hacer de España un país de progreso. Afortunadamente, la situación en España ha variado mucho desde los tiempos de Blanco White, pero la extensión y calidad de la educación es todavía uno de los temas importantes de la España de hoy en día, máxime desde la entrada de España en la Comunidad Económica Europea. Que la enseñanza en este país no es todo lo adecuada que debiera serlo es todavía un convencimiento extendido; Blanco se nos presenta como precursor de esta preocupación y, al tiempo, nos recuerda que un país libre y estable es un país en que los hábitos de lectura y las posibilidades de estudio están generalizados.

Finalmente queda la cuestión de la tolerancia religiosa. Si Blanco White es en alguna ocasión duro con los liberales por su poco sabio hacer político es en la enorme concesión a los serviles que supone el artículo 12 de la Constitución de Cádiz en la que se reconoce a la Religión Católica como única verdadera que debe ser protegida por el Estado. Blanco, que ha clamado contra la nefasta influencia de la Inquisición en España, ve ahora como la intolerancia se hace artículo constitucional en flagrante contraste con la afirmación de la supremacía de la nación. La dolorosa impresión que le produce este hecho produce uno de los artículos más emotivos de Blanco en El Español: «Tolerancia religiosa» ${ }^{19}$ donde se debate más allá de un caso personal, el suyo, el principio de la libertad de pensamiento y expresión. En este artículo, Blanco no deja de llamar a los liberales hipócritas, ya que está convencido de que muchos de ellos albergan dudas religiosas, como él. Su proceder ha condenado a todos los disidentes religiosos a la hipocresía permanente... o a abandonar el país, como fue su caso. No es sólo que la intolerancia sea anticristiana y anacrónica, sino que, lo más importante, existe una relación estrecha entre libertad religiosa y libertad civil:

Mirada la intolerancia religiosa por el aspecto religioso, ya hemos visto cuán opuesta es a los principios del cristianismo, y cuán directamente influye contra la santidad de sus misterios. Pero si la consideramos con respecto a los principios de la libertad civil que la nación española ha sancionado con leyes y está defendiendo con su sangre, la contradicción de intolerancia religiosa, y libertad individual es tan palpable, que no me pararé a otra que indicarla. Las Cortes españolas han declarado que la nación protege la religión católica por «leyes sabias y justas, y prohibe el ejercicio de cualquier otra»; y a mí entender ha declarado una contradicción imposible. Si las leyes que han formado o han de formar sobre esta materia no son reveladas (y que no lo son es claro, supuesto que la intolerancia no es de precepto divino) no puede haber en ellas, sean las que fueran, sino manifiesta injusticia. Las leyes no pueden prohibir sino lo que daña injustamente a otros: limitar la libertad individual sin este objeto es indudable tiranía. ¿Y habrá quien pruebe que el libre ejercicio de la religión que a cada uno dicta su conciencia daña a nadie civilmente? $»^{20}$.

Blanco llega a un extremo patético en su defensa de la tolerancia.

\footnotetext{
19 Ver Varela, E.: «Blanco White, la tolerancia y las Cortes de Cádiz», Cuadernos Hispanoamericanos 460 (octubre 1988), pp. 91-103.

${ }^{20}$ El Español 26, 1812, pp. 93-94.
} 
«Niéguese a los demás el ejercicio público si as lo juzgan conveniente los legisladores; pero por amor a la justicia y a los derechos sagrados de todo ciudadano, déjese a cada uno que profese los principios religiosos que le dicte su conciencia, y no se persiga a nadie porque meramente se separa de la comunión católica» ${ }^{21}$.

La contradicción está apuntada. Todo el edificio constitucional liberal cae por su base al permitir que la intolerancia se mantenga en España. Los liberales, por un lado se enfrentan con los serviles, con el rey a la cabeza, en su defensa de la soberanía popular, por otro lado se pliegan a la España negra al reconocerle la total autoridad religiosa. El problema de la religión, apunta Blanco, será el caballo de batalla entre liberales y conservadores en el futuro. La historia de España nos demuestra que esto ha sido así, y que solamente ahora, con el nuevo sistema constitucional, donde la religión católica ha perdido en gran medida su influencia se ha podido asentar un «sistema de libertades», pese a roces permanentes sobre temas puntuales. Actualmente en este país se vive un sistema de libertad de pensamiento y expresión y es esto, como ya apuntaba Blanco en su tiempo, lo que da estabilidad a la convivencia.

En esta rápida revisión de los temas de más actualidad de El Español, la visión de Blanco como intelectual que plantea con agudeza y precisión problemas fundamentales de España es de plena actualidad. Blanco señaló aspectos graves que había que corregir y que ahora, 170 años después parecen, finalmente, aunque no sin problemas, solucionados. Lo hizo, otro aspecto de su modernidad, desde su concepción de que la prensa debe ser libre y crítica en su papel de modeladora de la opinión pública, papel que ha de ser reconocido y apoyado por el Estado:

«La verdadera libertad se funda en la seguridad con que puede el escritor manifestar sus opiniones bajo el amparo de las leyes; ésta es la costumbre que tiene una nación de amar la libertad de hablar y escribir aunque con ello pierda todo individuo la esperanza de agregarse a un partido, que por ser dominante sea invulnerable. Esto, sólo puede formarse en España con el discurso del tiempo, y bajo la protección de un gobierno ilustrado" ${ }^{22}$.

Aquí nos encontramos con la esencia de la heterodoxia de Blanco: la perpetua crítica, el perpetuo debate de ideas convencido de que la esencia de la libertad es ejercitarla. Blanco tuvo que pagar un precio muy alto en su día por mantener esta actitud. Esperemos que éste no sea nunca más el caso en nuestro país.

${ }^{21}$ Ib. 26, 1812, p. 95.

${ }^{22}$ Ib. 5, 1810, p. 405. 